\title{
1 Viral assemblage variation in an Arctic shelf seafloor
}

2 Running Title: Viromes of Barents Sea sediment

3 Tan Thi Nguyen ${ }^{1,2}$, Espen Mikal Robertsen ${ }^{3}$, Bjarne Landfald ${ }^{2, *}$

4

${ }^{1}$ Centre for Research-based Innovation on Marine Bioactives and Drug Discovery (MabCent-SFI), UiT

The Arctic University of Norway, N-9037 Tromsø

${ }^{2}$ Norwegian College of Fishery Science, Faculty of Biosciences, Fisheries and Economics, UiT The Arctic

University of Norway, Breivika, N-9037 Tromsø, Norway

${ }^{3}$ NorStruct, Department of Chemistry, Faculty of Science and Technology, UiT The Arctic University of

Norway, Breivika, N-9037 Tromsø, Norway

*Corresponding author: bjarne.landfald@uit.no

ASTRACT: Spatial differences in microbial communities are observable even in habitats with moderate environmental variation, such as within the pelagic zone or seafloor of geographically finite regions of the oceans. Here we explore if biogeographical variations are manifested at this level also in the structure of viral assemblages by comparing DNA viromes from the Barents Sea upper seafloor, collected at five geographically separated locations. Twenty-seven to forty-four percent of the open reading frames showed significant similarity to genes of viral genomes in the Refseq database. The majority of the identified open reading frames, i.e. 86 to $95 \%$, were affiliated with sequences of single-stranded DNA (ssDNA) viruses, but the ssDNA virus genetic material was likely strongly overrepresented due to the use of phi29 DNA polymerase for amplifying viral DNA. The majority of ssDNA virus sequences originated from the Microviridae family of phages and the eukaryotic Circular Rep-encoding ssDNA (CRESS-DNA) viruses. The sediment virus assemblages showed higher overall similarity to counterparts from deep sea sediment of the Pacific Ocean than to 
27 e.g. Arctic Ocean pelagic viromes, supporting the presence of common compositional features

28 in sediment viral assemblages across continental-scale geographical separations. The Barents

29 Sea viromes grouped biogeographically in accordance with the south-north environmental

30 division of this Arctic sea by the oceanic polar front, thereby mirroring a corresponding $16 \mathrm{~S}$

31 rRNA gene based biogeographical division of the bacterial communities. However,

32 compositional differences in the eukaryotic virus assemblages rather than the bacteriophages

33 appeared as the primary basis for this spatial separation.

KEYWORDS: viruses; ssDNA virus; Barents Sea; marine sediments; biogeography 38 
40 Viruses and virus-like particles are the most abundant biological entities in marine ecosystems and they have an impact on processes like horizontal gene transfer, microbial community structuring and biogeochemical cycling (Bergh et al. 1989, Fuhrman 1999, Weinbauer 2004, Weinbauer \& Rassoulzadegan 2004, Suttle 2005, Bouvier \& del Giorgio 2007, Yang et al. 2010). Their genomes may have double-stranded (ds) or single-stranded (ss) DNA or ds or ss RNA. Traditionally the dsDNA group has been considered the most abundant in marine environments (Wommack \& Colwell 2000, Breitbart et al. 2002, Breitbart et al. 2004, Steward \& Preston 2011, Fancello et al. 2013). In recent years, high abundancies of ssDNA viruses have also been reported in various aquatic environments, including marine waters (Angly et al. 2006, Tucker et al. 2011, Labonté \& Suttle 2013a, b), fresh water (Lopez-Bueno et al. 2009, Roux et al. 2012), deep seafloor sediments (Yoshida et al. 2013) and methane seep sediments (Bryson et al. 2015). However, it has become increasingly clear that the high prevalence of ssDNA viruses to a large extent is a consequence of amplification bias caused by the use of phi29 DNA polymerase based multiple-displacement DNA amplification (MDA) to obtain sufficient metagenomic material for high-throughput sequencing (Kim \& Bae 2011). While the majority of marine dsDNA viral genomes range from 25 to 70 kilobases (kb) in size (Steward et al. 2000), circular ssDNA viruses are small both with respect to physical and genomic size, as the latter largely vary in the range from 1 to $9 \mathrm{~kb}$ (Fauquet et al. 2005). Subsequently, the ssDNA viruses are not easily enumerated by epifluorescent microscopy or flow cytometry viral counts because of weak fluorescence signal (Tomaru \& Nagasaki 2007, Holmfeldt et al. 2012). Temporal and geographical variations in aquatic viral assemblages are welldocumented (Bergh et al. 1989, Wommack \& Colwell 2000, Short \& Suttle 2003, Clasen et al. 2008, Danovaro et al. 2008, Yang et al. 2010, Helton et al. 2012, Parsons et al. 2012, 
Hurwitz et al. 2014) and these variations are at some level presupposed to be related to concomitant variations in the host communities although these relationships may be complex. Uncertainty factors include e.g. lytic versus temperate strategies of the viruses and $\mathrm{r}$ versus $\mathrm{K}$ type strategies of the hosts (Suttle 2007). Conceptual models like "kill the winner", implying that the fastest growing host populations in a community are the ones most susceptible to viral infections (Thingstad 2000), have been fruitful in explaining the viral contribution to maintenance of high host diversities in natural environments.

While there has been a vast increase in the available genomic information from marine microbiotas in the last decade owing to the implementation of next-generation sequencing technologies, the number of isolated and characterized virus-host systems is still limited. Due to their ecological importance marine primary producers, including the ubiquitous Prochlorococcus and Synechococcus among the prokaryotes and diatoms and dinoflagellates among the eukaryotes, have been principal targets of such studies (Sullivan et al. 2003, Nagasaki 2008, Avrani et al. 2011, Kimura \& Tomaru 2015). Among heterotrophic bacteria, phages infecting the Bacteroidetes species Cellulophaga baltica has been thoroughly characterized by Holmfeldt et al. (2007) and later infection studies of the ubiquitous, but hardto-cultivate pelagic groups SAR11 and SAR116 have been added to the list (Kang et al. 2013, Zhao et al. 2013). To evade the limitations caused by the consistent lack of cultivability of the large majority of marine prokaryotes, single-cell genomics based approaches have been introduced to identify and characterize individual bacterioplankton-virus systems (Roux et al. 2014b, Labonté et al. 2015). To our knowledge, no isolated virus-host system from marine sediments has been characterized.

Although a large fraction of the individual or contiguous gene sequences resulting from metagenomic sequencing projects on aquatic viromes have been classified as having unknown function and taxonomic affiliation (Breitbart et al. 2004, Edwards \& Rohwer 2005, 
Angly et al. 2006, Desnues et al. 2008, Lopez-Bueno et al. 2009, Roux et al. 2012, Fancello et al. 2013, Yoshida et al. 2013), such projects have still given valuable insights into compositional and biogeographical variations. The pioneering shotgun cloning based study by Breitbart et al. (2004) indicated a higher viral diversity in Californian coastal sediment than in the adjacent pelagic water masses. The two assemblage types were also phylogenetically distinct. Yoshida et al. (2013) have compared pyrosequence data from three deep-sea sediment viromes and conclude they show marked similarities that distinguish them from e.g. sea water viromes, despite spatial separations by more than $1000 \mathrm{~km}$ and marked host community and environmental differences.

The objective of the present study was to complement the hitherto fragmentary knowledge on diversity variations in seafloor viromes by adding data from an oceanic area that deviate both geographically and environmentally from the ones addressed in preceding studies in the field. Sampling at different sites, separated by up to $640 \mathrm{~km}$, in the Barents Sea shelf seafloor opened for elucidation of viral biogeographical variations within a coherent and environmentally moderately variable shelf sediment area. In a recent study based on the same sediment material, 16S rRNA gene based prokaryotic community variation was linked to the environmental and geographic separation of the Barents Sea by the oceanic polar front (Nguyen \& Landfald 2015). Hence, the present analysis opened the possibility of elucidating if coincident biogeographical patterns could be observed for bacterial and bacteriophage assemblages originating from the same material. 


\section{Sampling}

114 Sediment samples were collected by Van Veen grab within three days (20 - 23 of May 2009)

115 from five locations separated by up to $640 \mathrm{~km}$ (Fig. 1) in the western part of the Barents Sea.

116 The three southern sampling stations $(1-3)$ were south of the polar front, hence dominated by 117 relatively warm and saline Atlantic water (temperature $2.5-2.7^{\circ} \mathrm{C}$ at seafloor at time of 118 sampling), while the northern stations 4 and 5 were dominated by colder Arctic water 119 (temperature $\left.0.9-1.2^{\circ} \mathrm{C}\right)$. Furthermore, ocean depth was largest at the southern stations (442 $120474 \mathrm{~m}$ versus $230-290 \mathrm{~m}$ at the northern ones), while other recorded physicochemical variables

121 (salinity, grain size distribution, organic carbon content) showed minimal or inconsistent 122 differences between sampling sites. Additional details of sampling, locations and sediment characteristics are given in Nguyen \& Landfald (2015). The present stations 1 to 5 correspond to stations $1,3,4,7$ and 10 in that study.

Purification and isolation of viral DNA

127 Viral purification was performed with modifications of the procedure of Thurber et al. (2009).

128 Three $\mathrm{mL}$ sediment was suspended in $3 \mathrm{~mL}$ of $2 \%(\mathrm{v} / \mathrm{w})$ tetrasodium pyrophosphate and

129 incubated for $15 \mathrm{~min}$ in the dark at $4^{\circ} \mathrm{C}$. To ensure release of the viral particles from the

130 sediment samples, the suspension was sonicated on ice for $3 \times 45 \mathrm{sec}$ with a Branson 3210

131 sonicator (Triad Scientific, Inc. Manasquan, USA), and centrifuged at $1000 \mathrm{x} g$ for $5 \mathrm{~min}$.

132 Thereafter, the sediment pellets were twice re-suspended in $3 \mathrm{~mL}$ of $2 \%(\mathrm{v} / \mathrm{w}) \mathrm{NaCl}$ and

133 centrifuged at $2500 \mathrm{x}$ g for $5 \mathrm{~min}$. The supernatants were pooled and successively passed

134 slowly through $0.45 \mu \mathrm{m}$ and $0.2 \mu \mathrm{m}$ Whatman filters to remove residual cells. The filtrate was 135 concentrated by using a 30 kDa NMWCO centrifugal ultrafiltration device (Ultracel PL-30 
membrane, Millipore). The concentrate was treated with DNase I $\left(2.5 \mathrm{U} \mathrm{ml}^{-1}\right)$ and incubated

137 for 1 hour at $37^{\circ} \mathrm{C}$ to remove free DNA. To check for purity of the viral preparation, each

138 sample was stained with SYBRGold (Invitrogen) and inspected under an epifluorescence

139 microscope (Leica DM6000 B). If no contamination by prokaryotic cells was revealed, the

140 viral nucleic acids were extracted using the formamide and phenol/chloroform/isoamyl

141 alcohol procedure (Thurber et al. 2009). After the extraction, the absence of detectable

142 quantities of bacterial DNA was confirmed by subjecting the DNA preparation to PCR

143 amplification with universal bacterial 16S rRNA gene primers 27F (5'-

144 AGAGTTTGATCMTGGCTCAG-3') and 1492R (5'-TACCTTGTTACGACTT-3'). The PCR

145 master mix contained $2.5 \mu 1$ of $10 \mathrm{X}$ PCR buffer (Invitrogen, Waltham, MA, USA), $2.0 \mu 1$ of

$1460.2 \mathrm{mM}$ dNTPs (Invitrogen), $2.5 \mu 1$ of $0.5 \mu \mathrm{M}$ of each primer (Eurofins MWG, Ebersberg,

147 Germany), $1.25 \mathrm{U}$ of Taq polymerase (Invitrogen), $10 \mathrm{ng}$ of genomic DNA template, and

148 Milli-Q water to a total volume of $25 \mu 1$. The thermocycler (Applied Biosystems) conditions

149 were initial denaturation step at $95^{\circ} \mathrm{C}$ for $5 \mathrm{~min} ; 30$ cycles at $95^{\circ} \mathrm{C}$ for $30 \mathrm{~s}, 55^{\circ} \mathrm{C}$ for $30 \mathrm{~s}$, and

$15072^{\circ} \mathrm{C}$ for $1 \mathrm{~min}$; a final extension at $72^{\circ} \mathrm{C}$ for $5 \mathrm{~min}$. Only preparations where no bacterial cells

151 were observed and no bacterial PCR products were generated from the DNA extracts were

152 used for subsequent viral amplification.

154 Amplification of viral DNA and sequencing

155 Viral genomic DNA (10 ng) was amplified using the Genomiphi V2 DNA Amplication kit

156 (GE Healthcare Life Sciences, Freiburg, Germany) according to the manufacturer's

157 instructions. After amplification, amplicon DNA was purified on silica columns (Qiagen

158 Dnase Kit), precipitated with ethanol and resuspended in pure water. The concentration and

159 quality of amplified DNA were determined by a NanoDrop ND-1000 spectrophotometer

160 (Wilmington, DE, USA). The amplifications were done in duplicate for each sample to reduce 
161 bias. The samples were subjected to shotgun pyrosequencing (GS FLX Titanium; 454 Life

162 Sciences, Branford, CT, installed at The Norwegian High-Throughput Sequencing Centre,

163 University of Oslo, Norway; http://www.sequencing.uio.no).

165 Sequence assembly

166 Flowgram sequence data in sff format from the GS FLX Titanium were assembled using

167 Newbler version 2.5.3 for all five stations. Several runs with varying parameters were tested 168 to produce optimal assemblies based on N50 and total contig yield (bp). Default settings for 169 de novo assembly and "autotrimming" were considered the most successful. A minimum 170 contig size threshold of $500 \mathrm{bp}$ was applied to discard the smallest contigs.

\section{Taxonomic classifications}

173 The metagenomic sequence and contig data were analyzed using the Metavir (Roux et al.

174 2011) and Metavir2 (Roux et al. 2014a) pipeline (http://metavir-med.univbpclermont.fr/) with 175 taxonomic affiliations based on BLASTx queries in the NCBI Refseq complete viral genomes 176 protein sequence database (release of 2016-01-19). BLAST hits with E-values $<10^{-3}$ were

177 considered significant. Sequences affiliated with individual Circoviridae, Geminiviridae and 178 Nanoviridae genomes or metagenomic genomes categorized as Circular Rep-encoding 179 ssDNA (CRESS-DNA) viruses were classified as CRESS-DNA virus sequences in 180 accordance with Rosario et al. (2015). Taxonomic assignments were also generated via MG-

181 RAST (Meta Genome Rapid Annotation using Subsystem Technology, v3.1) (Meyer et al. 182 2008) based on BLASTx searches against the M5NR non-redundant database. An E-value cutoff of $10^{-3}$, a minimum identity cutoff of $60 \%$ and minimum alignment length of $15 \mathrm{bp}$ were used as parameters for this analysis. 
187 Phylogenetic analyses of marker genes

188 The protein sequences of the major capsid protein F (Vp1) of the Microviridae family

189 (Desnues et al. 2008) and the replication-associated protein (Rep) of the

190 Circoviridae/Nanoviridae/Geminiviridae families (Rosario et al. 2009a) were used to infer

191 phylogenetic trees. Representative sequences covering the whole or major parts of the

192 complete gene products from the Barents Sea sediment viromes were aligned with

193 homologous sequences obtained from translated genomic and metagenomic sequences of

194 public data and the Metavir server, by using the ClustalW algorithm in MEGA 6 program

195 package (Tamura et al. 2013). Phylogenetic trees were constructed using the maximum

196 likelihood method, with Jones-Taylor-Thornton substitution model, gamma distribution

197 among sites, partial deletion of missing data and bootstrapping with 100 resamplings, as

198 implemented in the MEGA package.

199

200 Comparative metagenomics of viral communities

201 The viral metagenomics data from our study were compared with public virome projects from 202 other environments, available in the MetaVir web server (Roux et al. 2011). The imported 203 data only included studies in which multiple displacement amplification (MDA) had been

204 used to increase DNA quantities and comprised data from deep-sea surface sediment 205 (Yoshida et al. 2013), sea water (Angly et al. 2006, Cassman et al. 2012) and fresh water 206 (Roux et al. 2012, Fancello et al. 2013). In the MetaVir workflow, the similarity of the virus 207 metagenomes were compared and scored as tBLASTx sequence similarity scores. Only 208 viromes that contained more than 50000 sequences with length exceeding $100 \mathrm{bp}$ on average 209 were used for the comparision. Similarity scores for two by two viromes were computed as 210 the sum of the best BLAST hit scores of a sequence component in one virome community 
against its counterpart in the other virome. The score sums for the virome pairs were stored in

212 a matrix format and used to hierarchically cluster the communities in the Metavir web server.

214 subgroups of virus sequences of the Barents Sea sediment data were inferred by the pvclust

215 package with default parameters (Suzuki \& Shimodaira 2006) in the R software

216 (http://www.r-project.org). Bootstrap values (1000 resamplings) were calculated.

218 Bacterial community comparisons. The total DNA was extracted using the PowerSoil ${ }^{\mathrm{TM}}$

219 DNA Isolation kit (Mo Bio Labs, Inc., Carlsbad, CA, USA) according to the manufacturer's

220 instruction. The bacterial $16 \mathrm{~S}$ rRNA genes were amplified by use the primers $27 \mathrm{~F}$ ( $5^{\prime}-$

221 AGAGTTTGATCMTGGCTCAG-3') and 338R (5'-TGCTGCCTCCCGTAGGAGT-3').

222 Subsequently, the amplicons were sequenced by multiplex pyrosequencing on a 454/Roche

223 GS-FLX Titanium instrument, and the sequences were binned into operational taxonomic

224 units (OTUs) at 97\% identity level, as described in Nguyen and Landfald (2015). Sequence-

225 based hierarchical clustering of the bacterial communities was done by average linkage in the

226 R package pvclust.

228 Virus/bacteria community relationships. Correlations between variations in bacterial

229 communities and viral assemblages (complete or subsections) were quantified as Spearman

230 rank correlation coefficients calculated from Bray-Curtis distance matrices. Bacterial

231 distances were based on OTU tables, while viral distances were based on tables of significant

232 BLAST hits $\left(\mathrm{E}<10^{-3}\right)$. The statistical significance of the correlations were tested by the

233 Mantel test with $10^{4}$ Monte Carlo permutations in the vegan package in $\mathrm{R}$. 
235 Virome accession numbers. Viral metagenomes from the five sampling stations are

236 accessible in the Metavir server under the name Barents Sea sediment. In the MG-RAST

237 annotation server, they are available under accession numbers: $4564380.3 ; 4564381.3$;

238 4564382.3; 4564383.3; 4565015.3. The 14 completed circular genomes are deposited in

239 GenBank under accession numbers KX828610 to KX829623.

\section{RESULTS AND DISCUSSION}

\section{The Barents Sea sediment virome}

247 The shotgun pyrosequencing produced a total of 674115 sequence reads with an average 248 length of $507 \mathrm{bp}$ from the five Barents Sea sediment samples (Table 1). Between $81 \%$ and $24987 \%$ of reads in the different samples were assembled into 17805 contiguous sequences 250 (minimum $500 \mathrm{bp}$ ) by the Newbler assembler. The median contig length varied in the range 2511131 to $1228 \mathrm{bp}$, the longest being $5745 \mathrm{bp}$. A total of 39756 complete or partial open reading 252 frames (ORFs) were identified in the contigs and 37 to $51 \%$ of the predicted ORFs in the 253 separate samples showed significant homology to sequences present in the NCBI Refseq 254 database. Fourteen contigs, ranging from 819 to $4217 \mathrm{bp}$ in size, were categorized as circular 255 genomes by employing the Metavir2 pipeline, but only four of them produced significant hits 256 (E-value $<10^{-3}$ ) to established viral genomes. The largest identified genome (4217 bp) was 257 similar to the one of the complete marine Gokushovirinae GOM (KC131021; Labonte \& 258 Suttle 2013a) while two genomes of size $2163 \mathrm{bp}$ and $1938 \mathrm{bp}$, respectively, showed highest 259 similarity to the eukaryotic circular Rep-encoding ssDNA (CRESS-DNA) viruses Avon- 
Heathcote Estuary associated circular virus 5 and 6 (KM874301 and KM874301) (Dayaram et 261 al. 2015). The former was categorized as circo-like by encoding both the conserved Rep and a 262 putative capsid (Cap) protein (Rosario et al. 2015) while the latter encoded just the Rep 263 protein, as did the fourth, smallest genome (1265 bp), which was similar to Circoviridae 3 264 LDMD-2013 (KF133810; McDaniel et al. 2014). Analyses of the individual sequences identified 27 to $44 \%$ as having significant similarity (BLASTx, E-values $<10^{-3}$ ) to genes within the complete viral genomes of the Refseq database (Table 1). Hence, both the contiguous and individual sequence data confirmed the consistent pattern from preceding environmental virome studies that the majority of sequences remain unassigned. However, the proportions of virus-affiliated sequences compared favorably with preceding metagenomic studies employing the Refseq 271 database, as $1-35 \%$ viral genes have been reported at $<10^{-3}$ significance level (Breitbart et al. 272 2002, Breitbart et al. 2004, Edwards \& Rohwer 2005, Angly et al. 2006, Desnues et al. 2008, Lopez-Bueno et al. 2009, Roux et al. 2012, Fancello et al. 2013, Yoshida et al. 2013).

Successful enrichment of viral metagenomic material was also indicated by low proportions of prokaryotic $(6.7 \%)$ and eukaryotic $(0.6 \%)$ sequences by search in the M5NR database of MG-RAST (Meyer et al. 2008). The rather straightforward method employed in the present study for isolation of virus particles from sediment therefore appeared efficient for enrichment 278 of viral genomic material. Further phylogenetic classification showed 86.1 to $94.8 \%$ of reads affiliated to viruses 280 from the five sampling stations to be confidently associated with ssDNA virus genes of the 281 Refseq database (E-value $<10^{-3}$ ), while reads of dsDNA virus origin constituted 3.0 to $11.6 \%$ 282 (Table 2). In accordance with the pattern for the ssDNA viral groups (see below), both a bacteriophage taxon (Caudovirales) and a eukaryote-infecting taxon (Phycodnaviridae) were represented among of the most predominant dsDNA groups. Several preceding metagenomic 
studies have indicated a strong presence of ssDNA viruses in marine environments (Desnues et al. 2008, Kim \& Bae 2011, Rosario \& Breitbart 2011, Tucker et al. 2011, Yoshida et al. 2013). However, a common feature of both the present and the referred studies is the use of MDA with phi29 polymerase for amplification of viral metagenomic DNA. MDA biases the genome type distribution towards ssDNA viruses and, in particular, towards small circular ssDNA viruses. For seawater samples this has been demonstrated by comparing viral DNA amplified by the linker amplified shotgun library (LASL) method of Breitbart et al. (2002) with the same samples amplified by MDA (Kim \& Bae 2011), while McDaniel et al. (2014) find large differences in abundances of ssDNA virus genes between MDA and unamplified DNA preparations from seawater. Chromatographic separation of viral groups prior to LASL amplification, as devised by Andrews-Pfannkoch et al. (2010), represents an improvement, but it still remains unclarified to what extent the diversities of the resulting metagenomic data are truly representative of the source material. In our study, the proportion of dsDNA viruses may have been lowered also by the filtration step used for removal of cellular and abiotic particles. Electron micrographs show some tailed or filamentous environmental virions to have physical dimensions that limit their passage through the $0.2 \mu \mathrm{m}$ pore size filters used in the present study (Bergh et al. 1989, Zhao et al. 2013), while circular ssDNA viruses are less likely hindered due to their overall smaller size. To secure the inclusion of large-size virions in the preparations, some recent virome studies have preferred the use of $0.45 \mu \mathrm{m}$ pore size filters or no filtration step at all (Lopez-Bueno et al. 2009, Fancello et al. 2013, Martínez Martínez et al. 2014). On the other hand, environmental viral diversity studies have also demonstrated variable proportions of ssDNA virus genes and even dominance of dsDNA virus genes in $0.2 \mu \mathrm{m}$ filtrates amplified by MDA (Rosario et al. 2009b, Cassman et al. 2012, McDaniel et al. 2014), indicating a relationship between abundances of ssDNA viruses in the source material and ssDNA virus genes in the amplified metagenome. Hence, the apparent 
predominance by ssDNA viral material in our amplified virome DNA likely reflects a lower

311 but substantial proportion of this virus group in the source material.

313 viruses into 11 families and one genus not assigned to a family (Krupovic \& Forterre 2015,

314 Krupovic et al. 2016). The BLASTx search affiliated the open reading frames of the Barents

315 Sea sediment material with six of these families, i.e. Microviridae, Circoviridae, Nanoviridae,

316 Germiniviridae, Parvoviridae and Inoviridae, among which the Microviridae phage family

317 constituted $8-44 \%$ whereas a larger fraction, $46-81 \%$, were assigned to the three eukaryotic

318 families of circular Rep-encoding ssDNA viruses (Circoviridae, Nanoviridae,

319 Germiniviridae), collectively named CRESS-DNA viruses (Rosario et al. 2015). More than

320 half of the CRESS DNA virus sequences were affiliated with the Circoviridae family by

321 showing highest similarity to genes in complete genomes carrying both Rep and putative 322 capsid encoding genes.

There are still rather few described examples of ssDNA viruses infecting marine

324 microorganisms, the first one being a novel virus that infects bloom-forming diatoms

325 (Nagasaki et al. 2005). More recently, putative Microviridae infecting marine Bacteroidetes

326 phylotypes have been reported (Holmfeldt et al. 2012). Identification of the virus-host

327 associations by in silico analysis generally requires complete or near-complete genomic

328 information of both virus and host (Roux et al. 2015). This is a challenging task by

329 metagenomic approaches even in rather well-characterized microbiotas like the human gut

330 (Pérez-Brocal et al. 2013), and even more so in highly diverse habitat types like marine

331 environments, which are dominated by hitherto uncultivated and genomically uncharacterized

332 phylogenetic groups. However, Mizuno et al. (2013) were able to assign putative hosts to

333 more than 500 viral conigs in a sea water fosmid library by combining several in silico

334 analytical approaches. Potential bacterial and archaeal hosts of viral assemblages in 
hydrothermal vent environments have been identified by clustered regularly interspaced short

336 palindromic repeat (CRISPR) analysis (Anderson et al. 2011), while Cassman et al. (2012)

337 were unable to identify virus-host pairs by CRISPR analysis in Pacific sea water material.

338 Recently single-cell genome amplification has been demonstrated as a viable new approach to

339 identify virus-bacteria associations even among the uncultivated majority of bacteria in a

340 pelagic marine system (Roux et al. 2014b).

\section{Marker gene phylogenies}

345 Phylogenetic relationships of the major capsid protein $\mathrm{F}(\mathrm{Vp} 1)$ as marker gene for the

346 Microviridae and the replication-associated protein (Rep) as marker gene for the CRESS-

347 DNA virus were inferred by comparing sequences covering conserved regions with

348 corresponding sequences from relevant metagenome and genome studies (Fig. 2A, B).

349 Gokushovirinae originating from intracellular parasitic bacteria (Chlamydiae, Bdellovibrio

350 and Spiroplasma spp.) (Brentlinger et al. 2002), and Microvirus from enterobacterial species

351 (including $\varphi \mathrm{X} 174$ ) were the sources of the most closely related Vp1 genes of established

352 genomic origin. The actual host groups of the Vp1-carrying phages within the Barents Sea

353 sediment communities were not established. A preceding study of bacterial community

354 structure in the same material identified Gammaproteobacteria and Deltaproteobacteria as

355 predominant groups by jointly constituting nearly two-thirds of the 16S rRNA gene pool

356 (Nguyen \& Landfald 2015). Outside the marine realm, the Microviridae have been shown to

357 infect a diverse range of hosts, including Proteobacteria, Spiroplasma and Chlamydiales

358 (Read et al. 2000, Brentlinger et al. 2002, Garner et al. 2004) and a recent, comprehensive

359 search for viral genomes in prokaryotic genomic data sets (Roux et al. 2015) also ties the 
Microviridae to Alpha-, Gamma- and Deltaproteobacteria as important hosts classes. It

361 therefore appears likely that the mentioned classes of Proteobacteria constitutes substantial parts of the Microviridae host range.

Different Barents Sea Rep-encoding sequences showed affiliation to both animal-

364 infecting (Circoviridae) and plant-infecting (Nanoviridae, ssDNA Alphasatellites,

365 Geminiviridae) genomic virus sequences and metagenomic sequences from sea water, fresh 366 water and deep-sea sediments were also distributed throughout the Rep gene diversity. No 367 distinct grouping of the picked Vp1 or Rep metagenomic sequences in accordance with the 368 south-north climatic division of the Barents Sea was observed, indicating that important 369 groups of host organisms were abundant throughout the sampling range.

\section{Community comparisons}

372 A hierarchical clustering tree, including both the five Barents Sea sampling sites and

373 additional aquatic and sediment viromes (Angly et al. 2006, Cassman et al. 2012, Roux et al. 374 2012, Fancello et al. 2013, Yoshida et al. 2013), was inferred from BLAST-based 375 comparisons (Fig. 3) by tools integrated in the MetaVir server (Roux et al. 2011). The three 376 Pacific Ocean marine sediment viromes (Yoshida et al. 2013) clustered with the Barents Sea 377 samples and the environmentally most comparable location, i.e. pelagic sediment (1181 m 378 water depth) off the Japanese coast, also showed the highest assemblage similarity. Even the 379 viromes from two extremely deep Pacific trenches were more similar to the Barents Sea 380 material than any sea water or freshwater sample, including the ones collected from Arctic 381 regions. These common phylogenetic features in seafloor sediment viromes across large 382 geographical separations and extensive variations in water depth likely reflect corresponding 383 similarities in the prokaryotic and eukaryotic host communities, but the specific basis for the 384 observed commonness remains vague as community data is lacking for the microorganisms. 
In the present study, some level of coincidence in bacterial and viral biogeography

386 patterns among the Barents Sea sediment sampling stations was indicated by the hierarchical

387 clustering patterns. A previous comprehensive study including 10 sampling stations,

388 established significant differences among bacterial communities in accordance with the main

389 environmental division of this ocean area into a southern and a northern region by the oceanic

390 polar front (Nguyen \& Landfald 2015). Here we reconfirmed this bacterial pattern in a study

391 comprising just the five stations included in the virome analysis. The two northernmost

392 stations 4 and 5 constituted a distinct cluster based on 16S rRNA gene sequence data (Fig.

393 4A). BLAST based similarity scores indicated the same partition of the viral assemblages if

394 the analysis was based on the complete virome sequence data (Fig. 3). However, if restricting

395 the analysis to the dominant group of bacteria-associated virus in the assemblages, i.e. the

396 Microviridae family of phages, the viromes showed no clustering pattern reflecting the one

397 exerted by the bacterial communities (Fig. 4B). On the other hand, the northern sampling

398 stations 4 and 5 showed a distinct grouping of the eukaryotic CRESS-DNA virus assemblages

399 (Fig. 4C), suggesting that these taxa were inclined to stronger host variations along the south-

400 north axis than the bacteria-infecting viruses. The absence of relationship between bacteria

401 and bacteriophage community variations was also confirmed by a Mantel test of correlation

402 between the respective community distance matrices $(\mathrm{P}=0.29)$. One factor that may have

403 contributed to this lack of coherence is the aforementioned expected bias towards ssDNA

404 virus in MDA-amplified viromes. This would lead to an overestimation of the importance of

405 the Microviridae as infective agents in the bacterial communities. Secondly, the bacterial

406 community profiling was based on ribosomal RNA gene frequency comparisons. This implies

407 that the phylogenetic distribution of actively proliferating bacterial phylotypes, which

408 expectedly are the more influential ones on phage assemblage structuring, may have deviated

409 from the observed total 16S rRNA gene based biogeographical variation. The elevated 
410 relative abundance of eukaryotic virus types in the north (Table 2) coincided with higher

411 levels of chlorophyll $a$ and chloroplast 16S rRNA gene frequencies at the same locations, as

412 reported elsewhere (Nguyen \& Landfald 2015). Hence, increased seafloor deposition of fresh

413 algal material in the northern region, due to the recent ice margin spring bloom, may have

414 contributed to the observed differences among the eukaryotic virus assemblages.

415 In conclusion, the study confirmed that virome biogeographical variation within a

416 coherent and environmentally moderately variable shelf seafloor area was small as compared

417 with differences among more distinctly separated ecosystems, such as geographically distant

418 lakes or oceans. It furthermore indicated some degree of commonness in composition of

419 seafloor viral assemblages at a global scale. The observed Barents Sea virome variation was

420 principally associated with changes in relative abundance and composition of eukaryotic

421 ssDNA virus genes, while the established bacterial community variation within the same

422 ocean range was not mirrored in the bacteriophage metagenomic material. Our work

423 underlined the need to complement this kind of community-wide approaches with

424 identification and characterization of representative virus-microorganism associations to get

425 comprehensive pictures of the interactions between the groups in their natural environment.

427 Acknowledgements. This work was supported by grants from the UiT-The Arctic University

428 of Norway, the Centre for Marine Bioactives and Drug Discovery (MABCENT-SFI) and the

429 program Marine Biotechnology in Northern Norway (MABIT). We thank the crew of F/F

430 Helmer Hansen for their technical and logistic assistance during the sampling cruise. 


\section{LITERATURE CITED}

Anderson RE, Brazelton WJ, Baross JA (2011) Is the genetic landscape of the deep subsurface biosphere affected by viruses? Front Microbiol 2:219

Andrews-Pfannkoch C, Fadrosh DW, Thorpe J, Williamson SJ (2010) Hydroxyapatitemediated separation of double-stranded DNA, single-stranded DNA, and RNA genomes from natural viral assemblages. Appl Environ Microbiol 76:5039-5045

Angly FE, Felts B, Breitbart M, Salamon P, Edwards RA, Carlson C, Chan AM, Haynes M, Kelley S, Liu H, Mahaffy JM, Mueller JE, Nulton J, Olson R, Parsons R, Rayhawk S, Suttle CA, Rohwer F (2006) The marine viromes of four oceanic regions. PLoS Biol 4:e368

Avrani S, Wurtzel O, Sharon I, Sorek R, Lindell D (2011) Genomic island variability facilitates Prochlorococcus-virus coexistence. Nature 474: 604-608.

Bergh O, Børsheim KY, Bratbak G, Heldal M (1989) High abundance of viruses found in aquatic environments. Nature 340:467-468

Bouvier T, del Giorgio PA (2007) Key role of selective viral-induced mortality in determining marine bacterial community composition. Environ Microbiol 9:287-297

Breitbart M, Felts B, Kelley S, Mahaffy JM, Nulton J, Salamon P, Rohwer F (2004) Diversity and population structure of a near-shore marine-sediment viral community. Proc Biol Sci 271:565-574

Breitbart M, Salamon P, Andresen B, Mahaffy JM, Segall AM, Mead D, Azam F, Rohwer F (2002) Genomic analysis of uncultured marine viral communities. Proc Natl Acad Sci U S A 99:14250-14255

Brentlinger KL, Hafenstein S, Novak CR, Fane BA, Borgon R, McKenna R, AgbandjeMcKenna M (2002) Microviridae, a family divided: Isolation, characterization, and 
genome sequence of phi $\mathrm{MH} 2 \mathrm{~K}$, a bacteriophage of the obligate intracellular parasitic bacterium Bdellovibrio bacteriovorus. J Bacteriol 184:1089-1094

Bryson SJ, Thurber AR, Correa AM, Orphan VJ, Vega Thurber R (2015) A novel sister clade to the enterobacteria microviruses (family Microviridae) identified in methane seep sediments. Environ Microbiol 17:3708-3721

Cassman N, Prieto-Davo A, Walsh K, Silva GG, Angly F, Akhter S, Barott K, Busch J, McDole T, Haggerty JM, Willner D, Alarcon G, Ulloa O, DeLong EF, Dutilh BE, Rohwer F, Dinsdale EA (2012) Oxygen minimum zones harbour novel viral communities with low diversity. Environ Microbiol 14:3043-3065

Clasen JL, Bigden SM, Payet JP, Suttle CA (2008) Evidence that viral abundance across oceans and lakes is driven by different biological factors. Freshw Biol 53:1090-1100.

Danovaro R, Corinaldesi C, Filippini, M, Fischer UR, Gessner MO, Jacquet S, Magangnini M, Velimirov B (2008) Viriobenthos in freshwater and marine sediments: a review. Freshw Biol 53:1186-1213.

Dayaram A, Goldstien S, Argüello-Astorga GR, Zawar-Reza P, Gomez C, Harding JS,

Desnues C, Rodriguez-Brito B, Rayhawk S, Kelley S, Tran T, Haynes M, Liu H, Furlan M, Varsani A (2015) Diverse small circular DNA viruses circulating amongst estuarine molluscs. Infect Genet Evol 31:284-295 Nature 452:340-343

Edwards RA, Rohwer F (2005) Viral metagenomics. Nat Rev Microbiol 3:504-510 
Fancello L, Trape S, Robert C, Boyer M, Popgeorgiev N, Raoult D, Desnues C (2013) Viruses in the desert: a metagenomic survey of viral communities in four perennial ponds of the Mauritanian Sahara. ISME J 7:359-369

Fauquet C, Mayo M, Maniloff J, Desselberger U, Ball L (2005) Virus Taxonomy. Eighth Report of the International Committee on Taxonomy of Viruses. San Diego, CA, USA: Academic Press.

Fuhrman JA (1999) Marine viruses and their biogeochemical and ecological effects. Nature $399: 541-548$

Garner SA, Everson JS, Lambden PR, Fane BA, Clarke IN (2004) Isolation, molecular characterisation and genome sequence of a bacteriophage (Chp3) from Chlamydophila pecorum. Virus Genes 28:207-214

Helton RR, Wang K, Kan J, Powell DH, Wommack KE (2012) Interannual dynamics of viriobenthos abundance and morphological diversity in Chesapeake Bay sediments. FEMS Microbiol Ecol 79:474-486

Holmfeldt K, Middelboe M, Nybroe O, Riemann L (2007) Large variabilities in host strain susceptibility and phage host range govern interactions between lytic marine phages and their Flavobacterium hosts. Appl Environ Microbiol 73:6730-6739

Holmfeldt K, Odic D, Sullivan MB, Middelboe M, Riemann L (2012) Cultivated singlestranded DNA phages that infect marine Bacteroidetes prove difficult to detect with DNA-binding stains. Appl Environ Microbiol 78:892-894

Hurwitz BL, Westveld AH, Brum JR, Sullivan MB (2014) Modeling ecological drivers in marine viral communities using comparative metagenomics and network analyses. Proc Natl Acad Sci U S A 111:10714-10719 
Kang I, Oh HM, Kang D, Cho JC (2013) Genome of a SAR116 bacteriophage shows the prevalence of this phage type in the oceans. Proc Natl Acad Sci U S A 110:1234312348

Kim KH, Bae JW (2011) Amplification methods bias metagenomic libraries of uncultured single-stranded and double-stranded DNA viruses. Appl Environ Microbiol 77:76637668

Kimura K, Tomaru Y (2015) Discovery of two novel viruses expands the diversity of singlestranded DNA and single-stranded RNA viruses infecting a cosmopolitan marine diatom. Appl Environ Microbiol 81:1120-1131

Krupovic M, Forterre P (2015) Single-stranded DNA viruses employ a variety of mechanisms for integration into host genomes. Ann NY Acad Sci 1341: 41-53

Krupovic M, Ghabrial SA, Jiang D, Varsani A (2016) Genomoviridae: a new family of widespread single-stranded DNA viruses. Arch Virol, 161 (9):2633-44

Labonté JM, Suttle CA (2013a) Metagenomic and whole-genome analysis reveals new lineages of gokushoviruses and biogeographic separation in the sea. Front Microbiol $4: 404$

Labonté JM, Suttle CA (2013b) Previously unknown and highly divergent ssDNA viruses populate the oceans. ISME J 7:2169-2177

Labonté JM, Swan BK, Poulos B, Luo H, Koren S, Hallam SJ, Sullivan MB, Woyke T, Wommack KE, Stepanauskas R (2015) Single-cell genomics-based analysis of virushost interactions in marine surface bacterioplankton. ISME J 9:2386-2399

Lopez-Bueno A, Tamames J, Velazquez D, Moya A, Quesada A, Alcami A (2009) High diversity of the viral community from an Antarctic lake. Science 326:858-861

Martínez Martínez J, Swan BK, Wilson WH (2014) Marine viruses, a genetic reservoir revealed by targeted viromics. ISME J 8:1079-1088 
McDaniel LD, Rosario K, Breitbart M, Paul JH (2014) Comparative metagenomics: natural populations of induced prophages demonstrate highly unique, lower diversity viral sequences. Environ Microbiol 16:570-585

Meyer F, Paarmann D, D'Souza M, Olson R, Glass EM, Kubal M, Paczian T, Rodriguez A, Stevens R, Wilke A, Wilkening J, Edwards RA (2008) The metagenomics RAST server - a public resource for the automatic phylogenetic and functional analysis of metagenomes. BMC Bioinformatics 9:386

Mizuno CM, Rodriguez-Valera F, Kimes NE, Ghai R (2013) Expanding the marine virosphere using metagenomics. PLoS Genet. 9

Nagasaki K, Tomaru Y, Takao Y, Nishida K, Shirai Y, Suzuki H, Nagumo T (2005) Previously unknown virus infects marine diatom. Appl Environ Microbiol 71:35283535

Nagasaki K (2008) Dinoflagellates, diatoms, and their viruses. J Microbiol: 46:235-43

Nguyen TT, Landfald B (2015) Polar front associated variation in prokaryotic community structure in Arctic shelf seafloor. Front Microbiol 6:17

Parsons RJ, Breitbart M, Lomas MW, Carlson CA (2012) Ocean time-series reveals recurring seasonal patterns of virioplankton dynamics in the northwestern Sargasso Sea. ISME J $6: 273-284$

Pérez-Brocal V, Garcia-Lopez R, Vazquez-Castellanos JF, Nos P, Beltran B, Latorre A, Moya A (2013) Study of the viral and microbial communities associated with Crohn's disease: a metagenomic approach. Clin Transl Gastroenterol 4:e36

Read TD, Brunham RC, Shen C, Gill SR, Heidelberg JF, White O, Hickey EK, Peterson J, Utterback T, Berry K, Bass S, Linher K, Weidman J, Khouri H, Craven B, Bowman C, Dodson R, Gwinn M, Nelson W, DeBoy R, Kolonay J, McClarty G, Salzberg SL, 
Eisen J, Fraser CM (2000) Genome sequences of Chlamydia trachomatis MoPn and Chlamydia pneumoniae AR39. Nucl Acids Res 28:1397-1406

Rosario K, Breitbart M (2011) Exploring the viral world through metagenomics. Curr Opin Virol 1:289-297

Rosario K, Duffy S, Breitbart M (2009a) Diverse circovirus-like genome architectures revealed by environmental metagenomics. J Gen Virol 90:2418-2424

Rosario K, Nilsson C, Lim YW, Ruan Y, Breitbart M (2009b) Metagenomic analysis of viruses in reclaimed water. Environ Microbiol 11:2806-2820

Rosario K, Schenck RO, Harbeitner RC, Lawler SN, Breitbart M (2015) Novel circular single-stranded DNA viruses identified in marine invertebrates reveal high sequence

Roux S, Faubladier M, Mahul A, Paulhe N, Bernard A, Debroas D, Enault F (2011) Metavir: a web server dedicated to virome analysis. Bioinformatics 27:3074-3075

Roux S, Enault F, Robin A, Ravet V, Personnic S, Theil S, Colombet J, Sime-Ngando T, Debroas D (2012) Assessing the diversity and specificity of two freshwater viral

Roux S, Tournayre J, Mahul A, Debroas D, Enault F (2014a) Metavir 2: new tools for viral metagenome comparison and assembled virome analysis. BMC Bioinformatics 15:76

Roux S, Hawley AK, Beltran MT, Scofield M, Schwientek P, Stepanauskas R, Woyke T, Hallam SJ, Sullivan MB (2014b) Ecology and evolution of viruses infecting ucultivated SUP05 bacteria as revealed by single-cell and meta-genomics. eLife 3:e03125

Roux S, Hallam SJ, Woyke T, Sullivan MB (2015) Viral dark matter and virus-host interactions resolved from publicly available microbial genomes. eLife. 4: e08490 
Short SM, Suttle CA (2003) Temporal dynamics of natural communities of marine algal viruses and eukaryotes. Aquat Microb Ecol 32:107-119

Steward GF, Montiel JL, Azam F (2000) Genome size distributions indicate variability and similarities among marine viral assemblages from diverse environments. Limnol Oceanogr 45:1697-1706

Steward GF, Preston CM (2011) Analysis of a viral metagenomic library from $200 \mathrm{~m}$ depth in Monterey Bay, California constructed by direct shotgun cloning. Virol J 8:287

Sullivan MB, Waterbury JB, Chisholm SW (2003) Cyanophages infecting the oceanic cyanobacterium Prochlorococcus. Nature 424:1047-1051

Suttle CA (2005) Viruses in the sea. Nature 437:356-361

Suttle CA (2007) Marine viruses--major players in the global ecosystem. Nat Rev Microbiol $5: 801-812$

Suzuki R, Shimodaira H (2006) Pvclust: an R package for assessing the uncertainty in hierarchical clustering. Bioinformatics 22:1540-1542

Tamura K, Stecher G, Peterson D, Filipski A, Kumar S (2013) MEGA6: Molecular Evolutionary Genetics Analysis version 6.0. Mol Biol Evol 30:2725-2729

Thingstad TF (2000) Elements of a theory for the mechanisms controlling abundance, diversity, and biogeochemical role of lytic bacterial viruses in aquatic systems. Limnol Oceanogr 45:1320-1328

Thurber RV, Haynes M, Breitbart M, Wegley L, Rohwer F (2009) Laboratory procedures to generate viral metagenomes. Nat Protoc 4:470-483

Tomaru Y, Nagasaki K (2007) Flow cytometric detection and enumeration of DNA and RNA viruses infecting marine eukaryotic microalgae. J Oceanogr 63:215-221

Tucker KP, Parsons R, Symonds EM, Breitbart M (2011) Diversity and distribution of singlestranded DNA phages in the North Atlantic Ocean. ISME J 5:822-830 
601 Weinbauer MG (2004) Ecology of prokaryotic viruses. FEMS Microbiol Rev 28:127-181

602 Weinbauer MG, Rassoulzadegan F (2004) Are viruses driving microbial diversification and 603 diversity? Environ Microbiol 6:1-11

604 Wommack KE, Colwell RR (2000) Virioplankton viruses in aquatic ecosystems. Microbiol $605 \quad$ Mol Biol Rev 64:69-114

606 Yang Y, Motegi C, Yokokawa T, Nagata T (2010) Large-scale distribution patterns of 607 virioplankton in the upper ocean. Aquat Microb Ecol 60:233-246

608 Yoshida M, Takaki Y, Eitoku M, Nunoura T, Takai K (2013) Metagenomic analysis of viral 609 communities in (hado)pelagic sediments. PLoS One 8:e57271

610 Zhao Y, Temperton B, Thrash JC, Schwalbach MS, Vergin KL, Landry ZC, Ellisman M, 611 Deerinck T, Sullivan MB, Giovannoni SJ (2013) Abundant SAR11 viruses in the $612 \quad$ ocean. Nature $494: 357-360$

613

614 
615 Table 1. Outcome of the virome sequence analyses at the individual sampling sites

\begin{tabular}{lccccc}
\hline $\begin{array}{l}\text { Sampling } \\
\text { site }\end{array}$ & $\begin{array}{l}\text { Number } \\
\text { of reads }\end{array}$ & $\begin{array}{c}\text { Average } \\
\text { length }(\mathrm{bp})\end{array}$ & $\begin{array}{c}\text { Assembled reads } \\
\text { (\% of reads) }\end{array}$ & $\begin{array}{c}\text { Number } \\
\text { of contigs }(>500 \mathrm{bp})\end{array}$ & $\begin{array}{c}\text { Viral hits }^{1} \\
\text { (\% of reads) }\end{array}$ \\
\hline ST.1 & 118313 & 497 & 81.3 & 3642 & 40.5 \\
ST.2 & 158119 & 511 & 80.1 & 5110 & 27.3 \\
ST.3 & 154403 & 516 & 78.5 & 4526 & 40.3 \\
ST.4 & 111206 & 502 & 79.9 & 2308 & 32.2 \\
ST.5 & 132074 & 509 & 86.6 & 2219 & 43.8 \\
\hline
\end{tabular}

616

617

618

619 
620 Table 2. Phylogenetic affiliations of viral sequences from the five sampling stations

\begin{tabular}{|c|c|c|c|c|c|c|}
\hline Group & Taxonomic composition & $\begin{array}{c}\text { ST.1 (\%) } \\
(\mathrm{n}=47948)\end{array}$ & $\begin{array}{c}\text { ST.2 }(\%) \\
(n=43193)\end{array}$ & $\begin{array}{c}\text { ST.3 }(\%) \\
(n=62148)\end{array}$ & $\begin{array}{c}\text { ST.4 (\%) } \\
(\mathrm{n}=36110)\end{array}$ & $\begin{array}{c}\text { ST.5 }(\%) \\
(n=57784)\end{array}$ \\
\hline \multirow[t]{5}{*}{ ssDNA } & Microviridae & 36.0 & 15.7 & 43.9 & 7.9 & 12.9 \\
\hline & CRESS-DNA virus & 57.8 & 69.7 & 45.7 & 81.2 & 81.4 \\
\hline & Parvoviridae & 0.1 & 0.1 & 0.1 & 0.0 & 0.0 \\
\hline & Inoviridae & 0.0 & 0.1 & 0.1 & 0.0 & 0.0 \\
\hline & Unclassified ssDNA viruses & 0.4 & 0.5 & 0.5 & 0.5 & 0.5 \\
\hline \multirow[t]{7}{*}{ dsDNA } & Phycodnaviridae & 2.4 & 6.3 & 1.9 & 2.1 & 1.1 \\
\hline & Caudovirales & 0.5 & 3.4 & 4.9 & 4.4 & 1.2 \\
\hline & Mimiviridae & 0.2 & 0.5 & 0.2 & 0.3 & 0.2 \\
\hline & Poxviridae & 0.2 & 0.5 & 0.2 & 0.2 & 0.1 \\
\hline & Herpesvirales & 0.1 & 0.2 & 0.2 & 0.1 & 0.1 \\
\hline & Iridoviridae & 0.1 & 0.1 & 0.1 & 0.0 & 0.0 \\
\hline & Unclassified dsDNA & 0.1 & 0.6 & 0.7 & 0.8 & 0.3 \\
\hline \multicolumn{2}{|c|}{ Satellites } & 1.7 & 2.1 & 1.1 & 2.1 & 2.0 \\
\hline \multicolumn{2}{|c|}{ ssRNA viruses } & 0.1 & 0.0 & 0.1 & 0.0 & 0.0 \\
\hline \multicolumn{2}{|c|}{ Unclassified viruses } & 0.3 & 0.2 & 0.3 & 0.4 & 0.2 \\
\hline \multicolumn{2}{|c|}{ Chloroplast 16S rRNA genes (\%)* } & 0.1 & 0.0 & 0.2 & 2.5 & 1.8 \\
\hline
\end{tabular}

$621 *($ Nguyen \& Landfald 2015); CRESS DNA, Circular Rep-encoding ssDNA 
Fig. 1. The western Barents Sea with geographical positions of sampling stations.

Fig. 2. Unrooted maximum likelihood phylogenetic trees computed from the major capsid

630 protein Vp1 of Microviridae (A) and the replication-associated protein (Rep) of CRESS-DNA

631 viruses (B). Marker coding: filled circles, sequences of the Barents Sea virome from southern

632 stations 1-3 (red) and northern stations 4-5 (blue); open circles, sequences from other

633 metagenomic projects, including fresh water (FW; Roux et al. 2012), sea water (SW; Labonté

634 \& Suttle 2013a, Labonté \& Suttle 2013b) and deep-sea sediment (DSS; Yoshida et al. 2013);

635 black triangles, sequences from completed genomes.

636

637 Fig. 3. tBLASTx similarity based comparison of environmental virome assemblages. All

638 included sequence data originate from multiple-displacement amplified viral DNA. Sources:

639 sea water (Angly et al. 2006, Cassman et al. 2012), deep-sea surface sediment (Yoshida et al.

640 2013), and fresh water (Roux et al. 2012, Fancello et al. 2013).

641

642 Fig. 4. Hierachical clustering of (A) bacterial communities, (B) Microviridae assemblages and

643 (C) CRESS-DNA virus assemblages of the Barents Sea sampling sites. Bacterial 16S rRNA

644 gene sequence data were obtained from Nguyen \& Landfald (2015). Multiscale bootstrap

645 values (1000 re-samplings) are indicated at the nodes.

646 


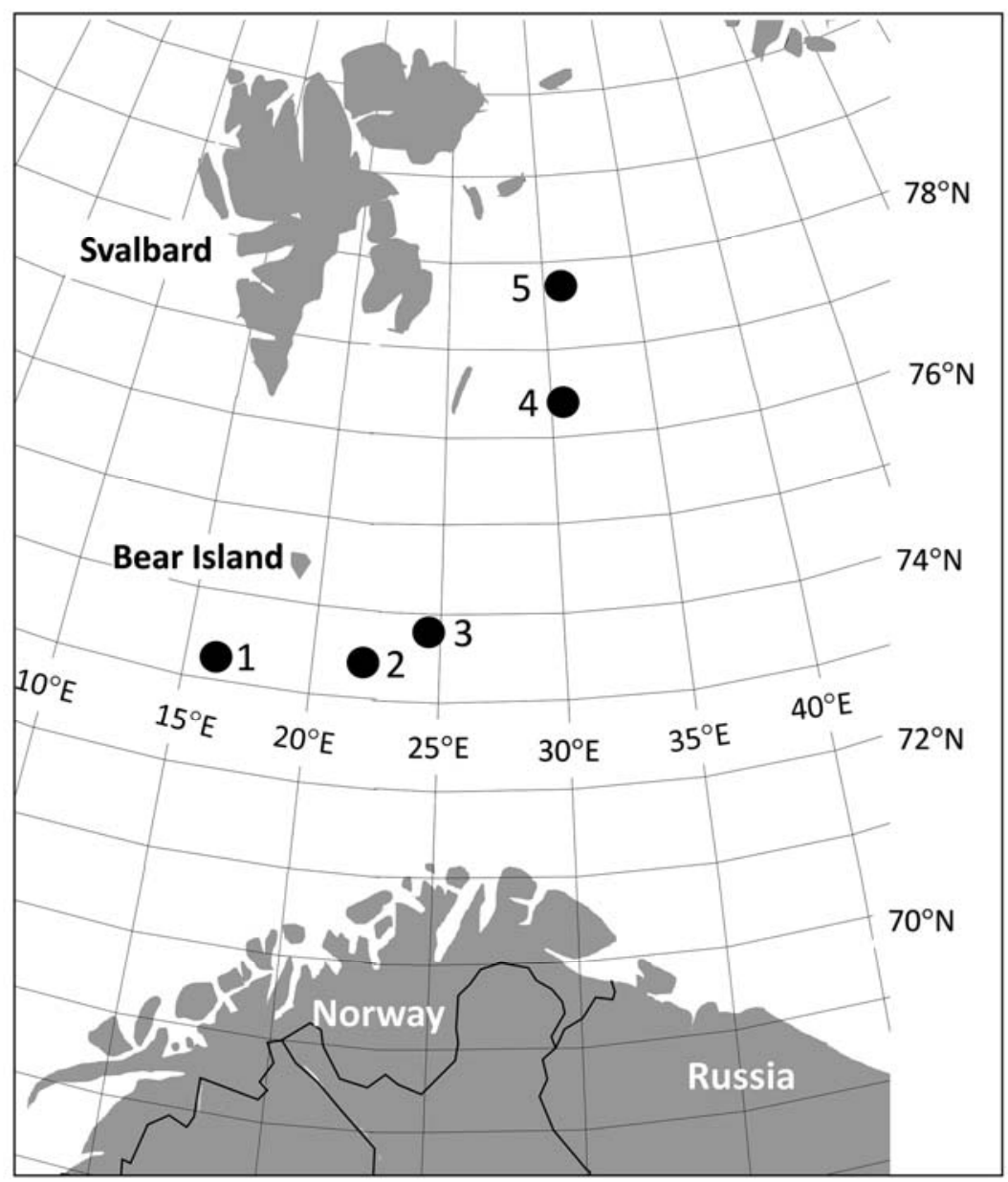

648

649

650

651

652

653

654

655

656 
657
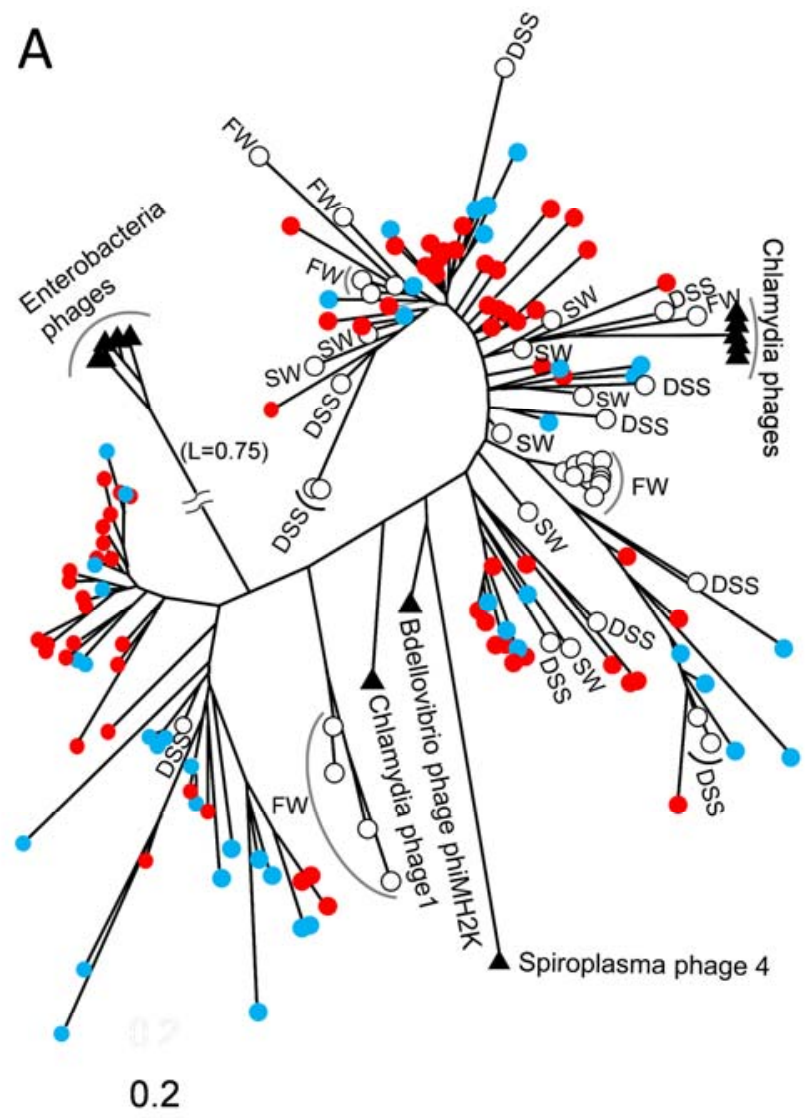

B

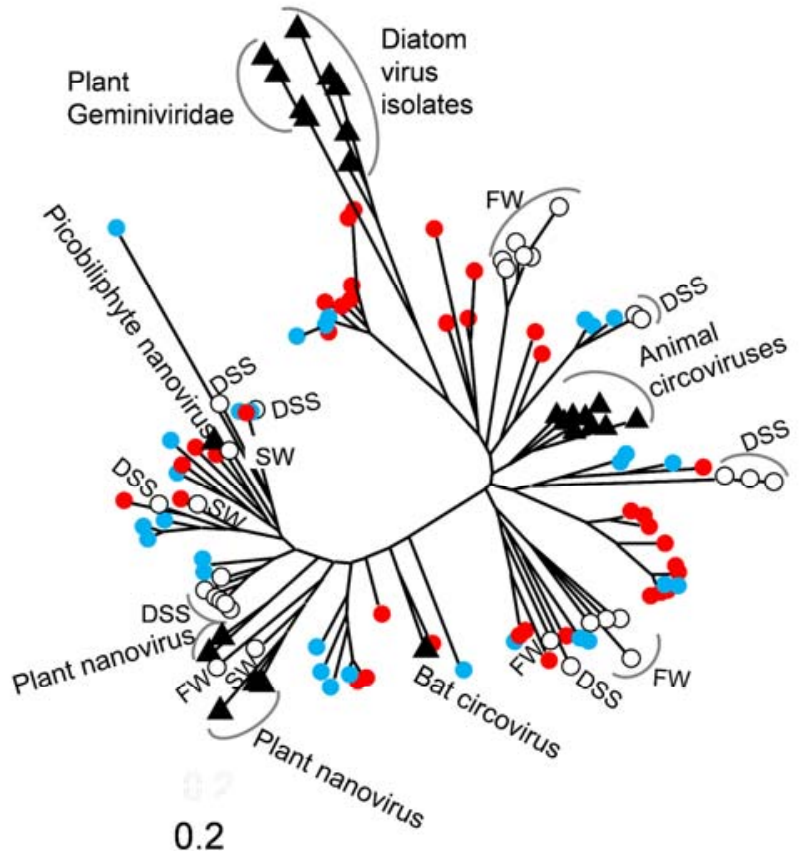

661 Fig. 2 


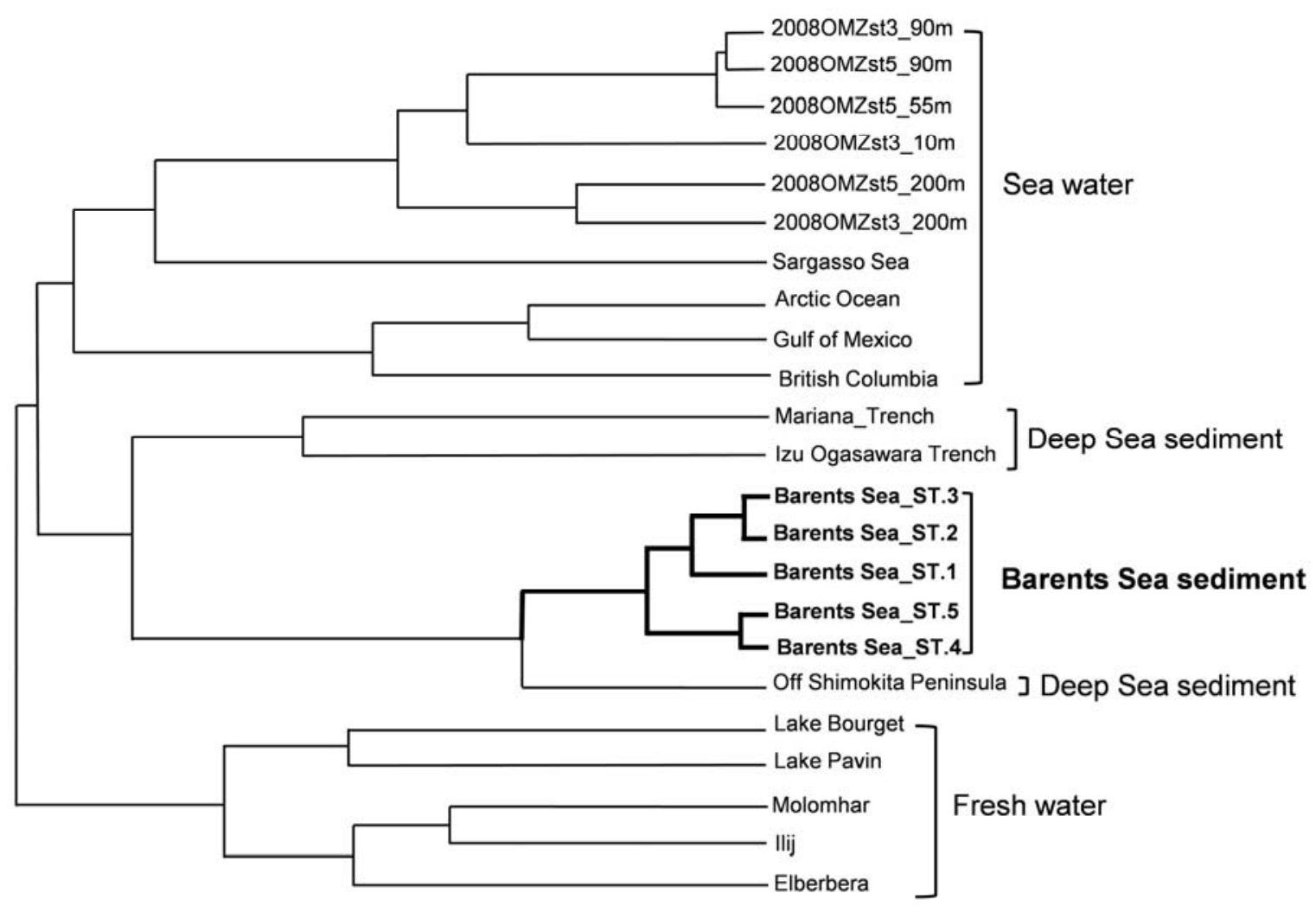

663

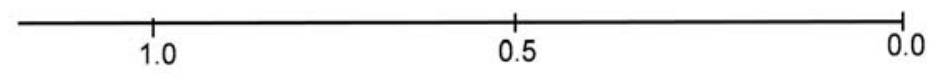

664

665

666

667

Fig.3

668 
669
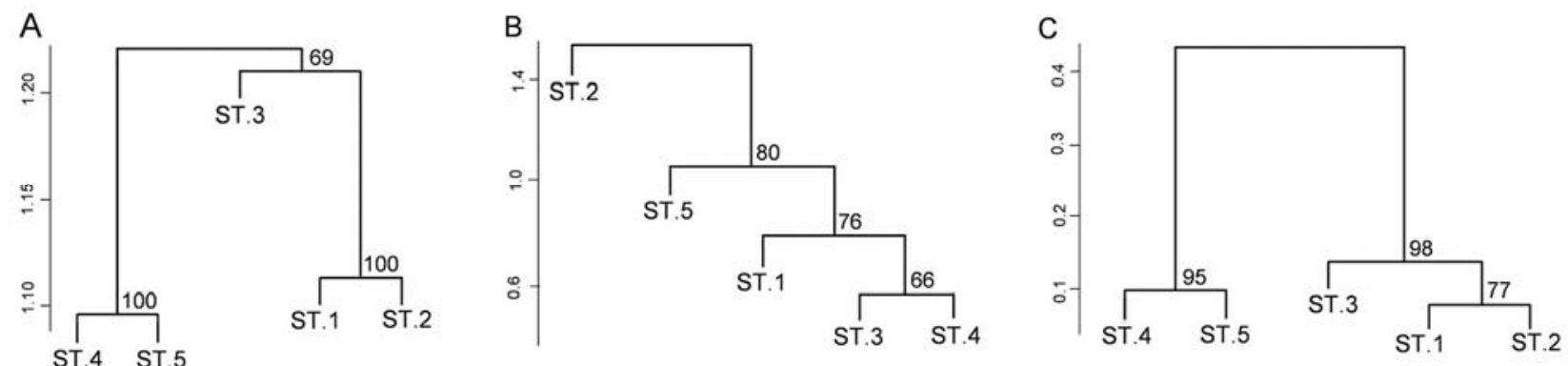

670

671

672

673

Fig.4 